\title{
Body mass index before kidney transplantation - principal risk factor for NODAT
}

\section{ABSTRACT}

Purpose. Pretransplant obesity is a well-known risk factor for post-transplant outcomes such as patient and graft survival, delayed graft function, rejection, and wound complications. According to the recommendations of the European Renal Best Practice, patients who have body mass index (BMI) value of more than $30 \mathrm{~kg} / \mathrm{m}^{2}$ before kidney transplantation should reduce their weight.

Materials and methods. In the group of 297 patients who had undergone primary kidney transplantation from post-mortem donors, we found that assessed the impact of BMI on the development of new onset diabetes after transplantation (NODAT). Additionally, relationships between immunosuppression, weight gain and BMI in patients after kidney transplantation were also analysed. We measured the value of the patients' BMI and weight before kidney transplantation, 12 months after kidney transplantation, and 5 years after kidney transplantation. The group contained only those patients who, at the time of the kidney transplantation, did not suffer from diabetes mellitus. According to the development of NODAT in the monitored period, the group of patients was divided

Address for correspondence: MU Dr. Juraj Miklušica, PhD.

Surgery Clinic and Transplant Center

University Hospital Martin

Kollárova 2, 03601 Martin

Slovak Republic

e-mail: juraj.miklusica@gmail.com

Phone: +421434203246

Clinical Diabetology 2016, 5, 1, 1-6

DOI: 10.5603/DK.2016.0001

Received: 10.12 .2015

Accepted: 09.02.2016 into the control group and NODAT group. We detected analysed the data on the type of immunosuppression (tacrolimus, cyclosporine A, mTOR inhibitor) and the average levels in the monitored period and identified whether BMI or increased weight 12 months and 5 years after kidney transplantation is related to the level (or dose) of the used immunosuppression.

Results. In our group, the patients who developed NODAT in the post-transplant period were significantly older in the 12-month analysis $(p<0.0001)$ and also in the 5-year analysis ( $p=0.0001)$; had higher $B M I$ at the time of transplantation ( $p=0.0003$ ) and higher BMI 12 months after kidney transplantation ( $p=0.0004)$ and a significantly higher weight gain 12 months after kidney transplantation ( $p=0.0469$ ). We discovered that neither the level of immunosuppression nor the dose of prednisone had any effect on the increase in BMI or weight gain during the monitored period.

Conclusion. The patients in the waiting list, who have any risk factors for the development of diabetes mellitus, should be informed how to eliminate these risk factors (weight control, diet, physical exercises, etc.). In addition to the above, all candidates for kidney transplantation are recommended to stop smoking, to control blood pressure, and perform a lipidogram. (Clin Diabet 2016; 5, 1: 1-6)

Key words: body mass index, immunosuppression, NODAT, kidney transplantation

\section{Introduction}

The risk factors of cardiovascular diseases are eliminated after kidney transplantation by the recovery of renal function. However, new risks factors occur at the same time, such as impaired glucose tolerance, diabetes 
Table 1. Risk factors for NODAT development [5]

\begin{tabular}{ll}
\hline Non-modifiable risk factors for NODAT & Modifiable risk factors for NODAT \\
\hline Age at the time of transplantation & Immunosuppression (corticosteroids, CNIs, mTOR inhibitors) \\
Population (Afro-Americans, Hispanics) & Obesity \\
Positive family history of DM2 & Hypertriacylglycerolaemia \\
Male gender & Artery hypertension \\
HLA A30, B27, B42 & Hypomagnesemia \\
Higher number of HLA mismatches & Prediabetes before transplantation \\
Polycystic kidney disease & Viral hepatitis C \\
& Cytomegalovirus infection \\
& Basiliximab in induction \\
\hline
\end{tabular}

DM2 - diabetes mellitus type 2; CNI - calcineurin inhibitor; mTOR - mammalian target of rapamycin

mellitus, arterial hypertension, lipid metabolism disorders, and other issues. The newly diagnosed diabetes mellitus after transplantation (NODAT) represents a serious and frequent complication in the transplantation of solid organs. The incidence varies from $4 \%$ to $25 \%$, depending on the transplanted organ, the duration of monitoring of the patient, and the used immunosuppression protocol [1-4]. Risk factors for NODAT are shown in Table 1.

The risk of cardiovascular (CVS) diseases in patients with NODAT is increased also by hyperlipoproteinaemia, arterial hypertension, or smoking. NODAT is connected also with other complications, namely: rejection of the graft, recurring infections, and worse long-term function of the graft $[5,6]$.

Pretransplant obesity is a well-known risk factor for post-transplant outcomes such as patient and graft survival, delayed graft function, rejection, and wound complications [7-11]. Several recent studies have shown that significant post-transplant weight gain is also a risk factor for the patient and for graft survival. Identifying patients at high risk of significant post-transplant weight gain and using various methods to help control their body weight may improve the patient and the graft survival [12-14].

According to the recommendations of the European Renal Best Practice (ERBP), patients with a body mass index (BMI) value of more than $30 \mathrm{~kg} / \mathrm{m}^{2}$ before kidney transplantation should reduce their weight.

There is uncertainty regarding the relationship between obesity and outcomes after kidney transplantation. Obese kidney transplant recipients may have poorer outcomes compared with non-obese recipients; however, the outcomes may be better compared with patients who remain on dialysis. There is no consensus on whether obesity should be an exclusion criterion for kidney transplantation, and the policies differ among transplant centres $[15,16]$.

\section{Materials and methods}

In the group of 297 patients (of Central European origin) who had undergone primary kidney transplantation from post-mortem donors (in the years 2003-2014) at the Transplantation Center in Martin, we measured their body mass index value and weight before kidney transplantation, 12 months and 5 years after kidney transplantation. The aim of the study was to determine the impact of BMI on the development of NODAT and relationships between immunosuppression level and weight gain and BMI in patients after kidney transplantation. The group included only those patients who, at the time of kidney transplantation, did not suffer from diabetes mellitus. According to development of NODAT in the monitored period, the group of patients was divided into the control group and the NODAT group. NODAT was diagnosed according to the American Diabetes Association's (ADA) criteria. The individually monitored parameters were compared in both groups. Furthermore, we noted the type of immunosuppression (tacrolimus, cyclosporine A, mTOR inhibitor), the average levels of immunosuppressive drugs, and the average dose of prednisone in the monitored period. By the correlation coefficient, we identified whether BMI or weight gain 12 months and 5 years after kidney transplantation is related to the level (or dose) of the used immunosuppression. In the statistical evaluation, we used the certified statistics program MedCalc version 13.1.2 and the following statistical analyses: student's t-test, chi-quadrate test, and correlation coefficient. We found the value of $p<0.05$ to be statistically significant.

\section{Results}

The group was composed of 297 patients who had undergone primary kidney transplantation from post-mortem donors and who were included in the 
12-month analysis, and 182 patients who had received a kidney transplant 5 years ago (5-year analysis). The data were collected on the presence of polycystic kidney disease as a cause of kidney failure, as well as the presence of hypertension and a family history of type 2 diabetes (parents, siblings, and grandparents). The mean levels of tacrolimus in the control group was $4.7 \pm 0.9 \mathrm{ng} / \mathrm{mL}$; in the NODAT group it was $4.8 \pm$ $\pm 1.2 \mathrm{ng} / \mathrm{mL}(p=0.5592)$. The mean cyclosporin $A$ levels in the control group was $86.9 \pm 44.6 \mathrm{ng} / \mathrm{mL}$; in the NODAT group it was $96 \pm 10.7 \mathrm{ng} / \mathrm{mL}(\mathrm{p}=0.7946)$. Mean sirolimus levels in the control group was $6.8 \pm$ $\pm 0.7 \mathrm{ng} / \mathrm{mL}$; in the NODAT group it was $6.7 \pm 0.5 \mathrm{ng} / \mathrm{mL}$ $(p=0.7210)$. Average daily dose of prednisone in the control group, was $8.2 \pm 2.3 \mathrm{mg} / \mathrm{day}$ and in the NODAT group it was $8.8 \pm 2.0 \mathrm{mg} /$ day $(p=0.1734)$.

\section{2-month analysis}

The average age of the patients at the time of kidney transplantation $(n=297)$ was $47.4 \pm 13.2$ years. The group comprised 187 males (63\%) and 110 females (37\%). There were 178 patients (59.9\%) with the average age of $43.7 \pm 12.8$ years in the control group. NODAT in the monitored period developed in 119 patients $(40.1 \%)$ with the average age of $51.1 \pm 13.6$ years $(p<0.0001)$. The value of BMl at the time of transplantation in the entire group was $24.9 \pm 4.9 \mathrm{~kg} / \mathrm{m}^{2}$. The value of BMI 12 months after kidney transplantation was $27.8 \pm 4.9 \mathrm{~kg} / \mathrm{m}^{2}$. The average value of BMI before kidney transplantation in the control group was 23.8 $\pm 4.7 \mathrm{~kg} / \mathrm{m}^{2}$, and in the NODAT group it was $25.9 \pm$ $\pm 5.1 \mathrm{~kg} / \mathrm{m}^{2}(p=0.0003)$. The value of BMI 12 months after kidney transplantation in the control group was $26.7 \pm 5 \mathrm{~kg} / \mathrm{m}^{2}$, and in the NODAT group it was $28.8 \pm 4.9 \mathrm{~kg} / \mathrm{m}^{2}(\mathrm{p}=0.0004)$. The average weight gain 12 months after kidney transplantation in the entire group was $5.5 \pm 5.2 \mathrm{~kg}$, in the control group it was $4.9 \pm 4.7 \mathrm{~kg}$, and in the NODAT group it was $6.1 \pm 5.6 \mathrm{~kg}(\mathrm{p}=0.0469)$. Polycystic kidney disease as a cause of renal failure was present in $10.4 \%$ of the control group and in $17.2 \%$ of the NODAT group $(p=0.2839)$. Arterial hypertension was diagnosed in $99.4 \%$ of the control group and $100 \%$ of the NODAT group ( $p=0.8866$ ). Positive family history for NODAT in the control group was present in $33.7 \%$ and in the NODAT group it was present in 50.4\% (0.0059).

\section{5-year analysis}

The average age of the patients at the time of kidney transplantation ( $n=182$ ) was $48 \pm 13$ years. There were 106 patients (58.2\%) with the average age of $44.1 \pm 12.2$ years in the control group. NODAT in the monitored period developed in 76 patients $(41.8 \%)$ with the average age $51.9 \pm 13.8$ years $(p=0.0001)$. The value of BMI 5 years after kidney transplantation in the control group was $27.9 \pm 5.1 \mathrm{~kg} / \mathrm{m}^{2}$. In the NODAT group it was $29.5 \pm 6.4 \mathrm{~kg} / \mathrm{m}^{2}(p=0.0624)$. The average weight gain 5 years after kidney transplantation in the entire group was $9.4 \pm 8.7 \mathrm{~kg}$, in the control group it was $8.6 \pm 7.7 \mathrm{~kg}$, and in the NODAT group it was $10.2 \pm 9.7 \mathrm{~kg}(p=0.2169)$ (see Tab. 1). By the correlation coefficient, we discovered that the average level of immunosuppression (tacrolimus, cyclosporine A, mTOR inhibitor, or the dose of prednisone) was not related to the BMI value and the increased weight (see Tab. 3-7).

\section{Discussion}

In our group, the patients who developed NODAT in the post-transplantation period were significantly older (both in the 12-month and the 5-year analysis), had higher $\mathrm{BMI}$ at the time of transplantation, higher

Table 2. Characteristics of the group

\begin{tabular}{|c|c|c|c|}
\hline 12-month analysis & Control group $(n=178)$ & NODAT $(n=119)$ & P value \\
\hline Age at the time of transplantation (years) & $43.7 \pm 12.8$ & $51.1 \pm 13.6$ & $<0.0001$ \\
\hline ADPKD (\%) & 10,4 & 17.2 & 0.839 \\
\hline Arterial hypertension (\%) & 99.4 & 100 & 0.8866 \\
\hline Positive family history of DM2 (\%) & 33.7 & 50.4 & 0.0059 \\
\hline $\mathrm{BMI}$ at the time of transplantation $\left[\mathrm{kg} / \mathrm{m}^{2}\right]$ & $23.8 \pm 4.7$ & $25.9 \pm 5.1$ & 0.0003 \\
\hline BMI 12 months after transplantation $\left[\mathrm{kg} / \mathrm{m}^{2}\right]$ & $26.7 \pm 5$ & $28.8 \pm 4.9$ & 0.0004 \\
\hline Weight gain 12 months from transplantation & $4.9 \pm 4.7$ & $6.1 \pm 5.6$ & 0.0469 \\
\hline 5-year analysis & Control group $(n=106)$ & NODAT $(n=76)$ & $P$ value \\
\hline Age at the time of transplantation (years) & $44.1 \pm 12.2$ & $51.9 \pm 13.8$ & 0.0001 \\
\hline BMI 5 years after transplantation $\left[\mathrm{kg} / \mathrm{m}^{2}\right]$ & $27.9 \pm 5.1$ & $29.5 \pm 6.4$ & 0.0624 \\
\hline Weight gain 5 years after transplantation $[\mathrm{kg}]$ & $8.6 \pm 7.7$ & $10.2 \pm 9.7$ & 0.2169 \\
\hline
\end{tabular}

ADPKD — polycystic kidney disease; DM2 - diabetes mellitus type 2 
Table 3. Correlation between BMI 12 months after transplantation and average level of immunosuppression

\begin{tabular}{lccc}
\hline BMI 12 months after transplantation & Correlation coefficient $\mathbf{r}$ & $\mathbf{9 5 \%}$ confidence interval for $\mathbf{r}$ & $\mathbf{P}$ value \\
\hline Level of tacrolimus & 0.06254 & -0.2816 to 0.3924 & 0.7253 \\
Level of cyclosporine A & 0.1087 & -0.7709 to 0.8457 & 0.8375 \\
Level of mTOR inhibitor & 0.09117 & -0.8603 to 0.9010 & 0.8841 \\
Dose of prednisone & 0.07241 & -0.08271 to 0.2241 & 0.3598 \\
\hline
\end{tabular}

Table 4. Correlation between BMI 5 years after transplantation and average level of immunosuppression

\begin{tabular}{lccc}
\hline BMI 5 years after transplantation & Correlation coefficient $\mathbf{r}$ & $\mathbf{9 5 \%}$ confidence interval for $\mathbf{r}$ & $\mathbf{P}$ value \\
\hline Level of tacrolimus & -0.1283 & -0.4471 to 0.2194 & 0.4697 \\
Level of cyclosporine A & -0.4138 & -0.9494 to 0.7379 & 0.4886 \\
Level of mTOR inhibitor & 0.3909 & -0.7500 to 0.9467 & 0.5152 \\
Dose of prednisone & -0.04342 & -0.1968 to 0.1120 & 0.5844 \\
\hline
\end{tabular}

Table 5. Correlation between weight gain 12 months after transplantation and average level of immunosuppression

\begin{tabular}{lccc}
\hline Weight gain 12 months after transplantation & Correlation coefficient $\mathbf{r}$ & 95\% confidence interval for $\mathbf{r}$ & $\mathbf{P}$ value \\
\hline Level of tacrolimus & 0.09826 & -0.1241 to 0.3113 & 0.3859 \\
Level of cyclosporine A & 0.1160 & -0.7678 to 0.8478 & 0.8267 \\
Level of mTOR inhibitor & 0.3849 & -0.7531 to 0.9459 & 0.5223 \\
Dose of prednisone & -0.09038 & -0.2412 to 0.06472 & 0.2527 \\
\hline
\end{tabular}

BMI 12 months after kidney transplantation, and significantly higher weight gain 12 months after kidney transplantation.

According to other studies, which agree with our study, the age at the time of kidney transplantation is considered to be an independent risk factor for the development of NODAT. Cosio et al. found a 2.2 times higher risk of the development of NODAT in recipients older than 45 years of age, compared to younger recipients [17]. The USRDS data show a strong relationship between the recipient's age and the development of NODAT. The recipients at the age of 45-59 years had a 1.9 times higher risk of the development of NODAT compared with recipients in the age of 18-33 years. In the recipients older than 60 years, the risk of the development of NODAT was 2 times higher than in the younger recipients [18].

Obesity before transplantation (defined as BMI $>30 \mathrm{~kg} / \mathrm{m}^{2}$ ) increases the risk of losing the graft. After transplantation, it increases the risk of cardiovascular diseases $[19,20]$. Weight gain is almost a rule in the patients after transplantation [21, 22]. According to the IDF criteria for metabolic syndrome, the waist circumference is the basic parameter. Obesity of potential recipients before transplantation is a frequent finding. A BMI value of more than $35 \mathrm{~kg} / \mathrm{m}^{2}$ represents a contraindication for kidney transplantation, and a $\mathrm{BMI}$ the value of $33-35 \mathrm{~kg} / \mathrm{m}^{2}$ represents a relative contraindication for transplantation, with necessary pretransplantation examination by a surgeon. Higher BMI values before transplantation are connected with insulin resistance after transplantation, and education of the patients on reduction of their weight before transplantation gives the opportunity for reduced risk of the development of NODAT and cardiovascular diseases [23-25].

In our group, we did not record any effect of the level of the used immunosuppression or the dose of prednisone on the BMI values after transplantation.

An interesting finding in our analysis is the fact that the levels of the used immunosuppression have no effect on increased BMI neither 12 months nor 5 years after kidney transplantation. Tacrolimus inhibits the reversible suppression of the secretion of insulin in the level of transcription of mRNA insulin by binding to the FK506 binding protein-12, which leads to subsequent inhibition of calcineurin in pancreas B-cells. A high concentration of FK506 binding protein-12 in pancreas may explain why tacrolimus inhibits secretion of insulin in higher rates than cyclosporine $A$. 
Table 6. Correlation between weight gain 5 years after transplantation and average level of immunosuppression

\begin{tabular}{lccc}
\hline Weight gain $\mathbf{5}$ years after transplantation & Correlation coefficient $\mathbf{r}$ & $\mathbf{9 5 \%}$ confidence interval for $\mathbf{r}$ & $\mathbf{P}$ value \\
\hline Level of tacrolimus & 0.1482 & -0.07394 to 0.3563 & 0.1896 \\
Level of cyclosporine A & 0.3949 & -0.7480 to 0.9472 & 0.5106 \\
Level of mTOR inhibitor & -0.9552 & -0.9971 to -0.4642 & 0.1013 \\
Dose of prednisone & 0.04812 & -0.1064 to 0.2004 & 0.5418 \\
\hline
\end{tabular}

Table 7. Comparison of graft function (creatinine and eGFR) 12 months after transplantation and 5 years after transplantation

\begin{tabular}{lccc}
\hline 12-month analysis & Control group $(\mathbf{n}=\mathbf{1 7 8})$ & NODAT $(\mathbf{n}=\mathbf{1 1 9})$ & P value \\
\hline Creatinine 12 months after transplantation $[\mu \mathrm{mol} / \mathrm{L}]$ & $139.4 \pm 38.1$ & $140.1 \pm 43.6$ & 0.9144 \\
eGFR 12 months after transplantation $[\mathrm{mL} / \mathrm{min}]$ & $51 \pm 14.4$ & $46.8 \pm 13.2$ & 0.0635 \\
\hline 5-year analysis & Control group $(\mathbf{n}=\mathbf{1 0 6})$ & NODAT group $(\mathbf{n}=\mathbf{7 6})$ & $\mathbf{P}$ value \\
\hline Creatinine 5 years after transplantation $[\mu \mathrm{mol} / \mathrm{L}]$ & $136.8 \pm 34.6$ & $137.3 \pm 40.3$ & 0.9423 \\
eGFR 5 years after transplantation $[\mathrm{mL} / \mathrm{min}]$ & $49.8 \pm 12$ & $46.8 \pm 12$ & 0.1794 \\
\hline
\end{tabular}

Our finding is supported also by the study by Rodriguez-Rodriguez et al. who confirm that the inhibitors of calcineurin have no effect on the patient's weight; however, the pro-diabetogenic effect related to this is visible particularly in patients who had insulin resistance already before transplantation [26]. Similarly, in regard to the level of immunosuppression, the dose of prednisone has no effect on increased BMI or weight gain. Based on the above findings, we may say that the patient's diet had a clear effect on weight after kidney transplantation.

\section{Conclusion}

In our group, we identified BMI and weight gain as the risk factors for NODAT both in the 12-month and the 5-year analysis. Screening of the risk factors for development of diabetes mellitus should be performed before inserting the patient in the waiting list. It is also recommended to perform oral glucose tolerance test (OGTT) in patients with normal fasting glycaemia. Therefore, patients on the waiting list who have risk factors for the development of diabetes mellitus should be informed about the elimination of these risk factors (weight control, diet, physical exercises, etc.). In addition to the above, standard recommendations to all candidates for kidney transplant include the following: to stop smoking, to control blood pressure, and to perform a lipidogram.

\section{REFERENCES}

1. Davidson J, Wilkinson AH, Dantal J et al. New-onset diabetes after transplantation: 2003 International Consensus Guidelines. Transplantation 2003; 7: SS3-SS24.

2. Baid $S$, Cosimi AB, Farrel ML et al. Posttransplant diabetes mellitus in liver transplant recipients: risk factors, temporal relationship with hepatitis $C$ virus allograft hepatitis, and impact on mortality. Transplantation 2001; 72: 1066-1072.

3. Knobler $\mathrm{H}$, Stagnaro-Green $\mathrm{A}$, Wallenstein $\mathrm{S}$ et al. Higher incidence of diabetes in liver transplant recipients with hepatitis C. J Clin Gastroenterol 1998; 26: 30-33.

4. Ye X, Kuo H-T, Sampaio MS et al. Risk factors for the development of new-onset diabetes mellitus after transplant in adult lung transplant recipients. Clin Transplant 2010; 1111: 1-7.

5. Hjelmesaeth J, Hartmann A, Leivestad T. The impact of earlydiagnosed new-onset post-transplantation diabetes mellitus on survival and major cardiac events. Kidney Int 2006; 69: 588-595.

6. Kantárová D, Vrlík M, Buc M. Genetic determination and immunopathodevelopment of type 1 diabetes mellitus in humans. Acta Medica Martiniana 2012; 12: 19-31.

7. Meier-Kriesche HU, Arndorfer JA, Kaplan B. The impact of body mass index on renal transplant outcomes: a significant independent risk factor for graft failure and patient death. Transplantation 2002; 73: 70-74.

8. Aalten J, Christiaans $\mathrm{MH}$, de Fijter $\mathrm{H}$ et al. The influence of obesity on short- and long-term graft and patient survival after renal transplantation. Transplantation 2006; 19: 901-907.

9. Papalia T, Greco R, Lofaro D, Maestripieri S, Mancuso D, Bonofiglio R. Impact of body mass index on graft loss in normal and overweight patients: retrospective analysis of 206 renal transplants. Clin Transplant 2010; 24: E241-E246.

10. Gore JL, Pham PT, Danovitch GM et al. Obesity and outcome following renal transplantation. Am J Transplant 2006; 6: 357-363.

11. Grosso G, Corona D, Mistretta A et al. The role of obesity in kidney transplantation outcome. Transplant Proc 2012; 44: 1861-1868.

12. El-Agroudy AE, Wafa EW, Gheith OE, Shehabel-Dein AB, Ghoneim MA. Weight gain after renal transplantation is a risk factor for patient and graft outcome. Transplantation 2004; 77: 1381-1385. 
13. Cosio FG, Pesavento TE, Osei K, Henry ML, Ferguson RM. Posttransplant diabetes mellitus: increasing incidence in renal allograft recipients transplanted in recent years. Kidney Int 2001; 59: 732-737.

14. Marrero D, Hernandez D, Tamajón LP et al.; for the Spanish Late Allograft Dysfunction Study Group. Pre-transplant weight but not weight gain is associated with new-onset diabetes after transplantation: a multi-centre cohort Spanish study. NDT Plus 2010; 3: ii15-ii20.

15. ERBP Guideline On The Management And Evaluation Of The Kidney Donor And Recipient. Nephrol Dial Transplant 2013; 28: ii1-ii71. doi: 10.1093/ndt/gft218

16. Grandtnerová B, Laca L', Gábor D, Gregová E, Korónyi S. Folic acid supplementation and homocyst(e)ine level in renal trans-plant recipients. Transplantation Proceedings 2001; 33: 2049-2050 .

17. Cosio FG. Post-transplant diabetes mellitus: increasing incidence in renal allograft recipients transplanted in recent years. Kidney Int 2001; 59: 732-737.

18. Kasiske BL. Diabetes mellitus after kidney transplantation in the United States. Am J Transplant 2003; 3: 178-185.

19. Vojtková J, Durdík P, Michnová Z, Turčan T, Čiljaková M. Exhaled carbon monoxide in adolescents with diabetic cardiovascular autonomic neuropathy. J Pediatr Endocrinol Metab 2014; 27: 709-715.

20. Meier-Kriesche HU, Arndorfer JA, Kaplan B. The impact of body mass index on renal transplant outcomes: a significant independent risk factor for graft failure and patient death. Transplantation 2002; 73: 70-74.

21. Clunk JM, Lin CY, Curtis JJ. Variables affecting weight gain in renal transplant recipients. Am J Kidney Dis 2001; 38: 349-353.

22. Potluri K, Hou S. Obesity in kidney transplant recipients and candidates. Am J Kidney Dis 2010; 56: 143-156.

23. Cashion AK, Sanchez ZV, Cowan PA, Hathaway DK, Lo Costello A, Gaber AO. Changes in weight during the first year after kidney transplantation. Prog Transplant 2007; 17: 40-47.

24. Leavey SF, McCullough K, Hecking E et al. Body mass index and mortality in 'healthier' as compared with 'sicker' haemodialysis patients: results from the Dialysis Outcomes and Practice Patterns Study (DOPPS). Nephrol Dial Transplant 2001; 16: 2386-2394.

25. Salahudeen AK. Obesity and survival on dialysis. Am J Kidney Dis 2003; 41: 925-932

26. Rodriguez-Rodriguez AE, Triñanes J, Velazquez-Garcia J et al. The higher diabetogenic risk of tacrolimus depends on pre-existing insulin resistance. A study in obese and lean Zuckerrats. Am J Transplant 2013; 13: 1665-1675. 